\title{
A VITALICIEDADE DO POSTO DE OFICIAL DAS FORÇAS ARMADAS COMO INSTRUMENTO DE CONCRETIZAÇÃO DOS DIREITOS SOCIAIS NA ORDEM ECONÔMICA, PREVIDENCIÁRIA E TRIBUTÁRIA
}

\author{
Milena Zampieri Sellmann ${ }^{1}$ \\ Raphael Ramos Passos ${ }^{2}$
}

\section{RESUMO}

A temática intenciona identificar quais prerrogativas recaem sobre a conservação do posto pelo oficial das Forças Armadas brasileiras, mesmo após eventual incursão em condutas consideradas indesejáveis para o perfil desta categoria de agente. Há que se considerar a prerrogativa da vitaliciedade para conservação do posto em contraposição à mera estabilidade, no sentido da destituição do cargo ocorrer somente após pronunciamento judicial. Engloba aspectos concernentes ao direito social previdenciário e trabalhista dos militares federais. Visa a estudar o impacto da incidência de alguns encargos previdenciários e tributários sobre a carreira do militar, com a finalidade de quebrar alguns paradigmas.

Palavras-chave: Militar. Oficial. Vitaliciedade. Tributos. Previdência.

\section{THE VITALICIETY OF THE OFFICIAL OFFICE OF THE ARMED FORCES AS AN INSTRUMENT FOR THE CONCRETIZATION OF SOCIAL RIGHTS IN THE ECONOMIC, SOCIAL SECURITY AND TAXATION ORDER}

\begin{abstract}
The thematic aims to identify which prerogatives fall on conservation of post by officer of the Brazilian Armed Forces, even after possible incursion into conduits considered undesirable for profile of this category of agent. It is necessary to consider prerogative of life for conservation of post as opposed to stability, in sense of dismissal of post occur only after pronouncement. It encompasses aspects concerning social security and labor law of federal
\end{abstract}

\footnotetext{
${ }^{1}$ Especialista, Mestre e Doutora em Direito Tributário pela PUC/SP. MBA na área de gestão universitária. Extensão Universitária em Boston College, Laspau, University of Toronto, University of London, University of Southern California, Hong kong Institute of Education, Center for World-Class Universities of Shanghai Jiao Tong University e Université Paris - Est Créteil. Graduada em Direito pelo Centro Universitário Salesiano de São Paulo - U. E. de Lorena/SP. Advogada tributarista, preventiva e contenciosa, até março de 2018. Professora de Direito Tributário nos Cursos de Graduação e Pós-graduação (lato sensu e stricto sensu) em Direito do Centro Universitário Salesiano de São Paulo - U. E. de Lorena/SP, instituição na qual também atuou como Coordenadora do Curso de Direito. Professora de Direito Tributário e Prática Tributária no Damásio Educacional. Aprovada nos Concursos Públicos de Provas e Títulos para Outorga de Delegações de Notas e de Registro do Estado de Minas Gerais - Editais 01/2011 e 01/2014. Tabeliã e Oficiala no Estado de Minas Gerais. Rua Dom Bôsco, 284, Lorena - SP. E-mail: milenasellmann@hotmail.com.

20 autor é Tenente-Coronel do Exército Brasileiro, formado pela Academia Militar das Agulhas Negras (AMAN) e especialista em Operações Militares pela Escola de Aperfeiçoamento de Oficiais (EsAO). É bacharel em Direito pela Universidade Federal de Juiz de Fora (UFJF), especialista em Direito Militar pela Universidade Gama Filho (UGF) e mestrando em Direito pelo Centro Universitário Salesiano de São Paulo (UNISAL). Possui o curso de Direito Internacional dos Conflitos Armados - Direito Internacional Humanitário (DICA - DIH) pela Escola Superior de Guerra (ESG). É administrador, registrado no Conselho Regional de Administração do Rio de Janeiro (CRA - RJ) sob a matrícula 20-93108. É professor permanente de Direito na Academia Militar das Agulhas Negras (AMAN). Rodovia Presidente Dutra, Km 306, Resende-RJ. E-mail: raphaelramospassos@gmail.com.
} 
military. It aims to study impact of incidence of some social security and tax charges on career of military, with the purpose of breaking paradigms.

Keywords: Military. Official. Vitality. Taxes. Social security.

\section{INTRODUÇÃO}

O presente artigo científico, inserido nos trabalhos desempenhados no grupo de pesquisa "Direitos Sociais, Direitos Fundamentais e Políticas Públicas" da Faculdade de Direito do Centro Universitário Salesiano de São Paulo (UNISAL), tem por objetivo apresentar uma visão sobre a garantia de permanência no posto do oficial das Forças Armadas brasileiras (Exército, Marinha e Aeronáutica), em tempo de paz, em conformidade com a atual Constituição da República Federativa do Brasil de 5 de outubro de 1988. Esta garantia é um dos aspectos que compõem o sistema de proteção social ("previdenciário") dos militares das Forças Armadas.

Com o escopo de explicitar os instrumentos que conduziram à abordagem do tema proposto, passaremos a discorrer acerca da metodologia de pesquisa científica a ser empregada. Relativamente à sua classificação, apontamos que o trabalho, do ponto de vista de sua natureza, foi elaborado na forma de pesquisa básica, pois objetivou gerar conhecimentos novos úteis para o avanço da ciência do Direito, envolvendo verdades e interesse universais. Da perspectiva da forma de abordagem do problema, temos uma pesquisa qualitativa, por considerarmos que há uma relação dinâmica entre o ambiente e o objeto de estudo, ou seja, uma ligação indissociável entre a objetividade fática e a subjetividade filosófica, sendo intraduzível em algoritmos numéricos. Cresceram de importância a interpretação dos fenômenos jurídicos, filosóficos, históricos e sociais e a consequente atribuição de significados. Tendo como focal os objetivos da investigação, a proposta foi de uma pesquisa eminentemente exploratória, haja vista a necessidade de se proporcionar maior familiaridade com os problemas envolvendo os princípios dos Direitos Sociais, tornando-os explícitos e construindo hipóteses a serem validadas ou descartadas. $\mathrm{O}$ procedimento técnico adotado foi a pesquisa bibliográfica, justificando-se por ser o estudo sustentado por material já publicado, principalmente, as obras clássicas. A pesquisa bibliográfica teve fundamental importância, especialmente por procurarmos extrair as informações de livros doutrinários voltados para a área dos Direitos Sociais, bem como de leis, jurisprudências, e sites da internet. Foi adotado, como método científico, o proposto pelos racionalistas Descartes, Spinoza e Leibniz: o método dedutivo. Foi perfeitamente compatível com a análise dos diversos conceitos 
propostos pelos doutrinadores, ao planear explicar o conteúdo das diversas premissas, por intermédio do silogismo. Os dados, por serem, em sua maioria, bibliográficos, foram coletados em bibliotecas públicas e privadas em Resende - RJ e Lorena - SP, principalmente nos acervos da Faculdade de Direito do Centro Universitário Salesiano de São Paulo (UNISAL) e da Academia Militar das Agulhas Negras (AMAN). Os principais livros citados neste projeto foram adquiridos, e estão permanentemente à disposição para consulta. Houve a disponibilidade de acesso à internet com conexão de banda larga no local de estudos, com a finalidade de localizar material pertinente ao trabalho e proceder à sua impressão e arquivamento, quando foi o caso. Os textos foram enfocados de maneira crítica ou reflexiva, procurando testar as teorias preconizadas com a realidade sociológica em vigor, ou mesmo, com outras teorias de autores adeptos de correntes doutrinárias divergentes. Os dados foram analisados pela leitura e sistema de fichamento do material considerado pertinente, com a confecção de resumos e consequente arquivamento em local próprio para este fim. Os arquivos digitais foram armazenados em mídia eletrônica, possibilitando uma oportunidade rápida de consulta, inclusive remotamente, em relação ao local de estudos. Com a finalidade de melhor elucidar o objeto do estudo, a análise dos dados buscou uma aproximação com a realidade, na expectativa de se compreender o significado da ação humana e não somente se conformar com sua descrição. Foi viável, desta forma, a extração de considerações e conclusões a respeito do tema.

Este trabalho pretende interpretar, à luz da Carta Magna, os dispositivos presentes no Decreto-Lei 1.001, de 21 de outubro de 1969 - Código Penal Militar (CPM); Decreto-Lei 1.002, de 21 de outubro de 1969 - Código de Processo Penal Militar (CPPM), Lei 5.836/72 Dispõe sobre o Conselho de Justificação e dá outras providências; Lei 6.880/80 - Estatuto dos Militares; Lei 8.457/92 - Lei de Organização Judiciária Militar; Lei Complementar 75/93 Estatuto do Ministério Público da União; Regimento Interno do Superior Tribunal Militar (RISTM); bem como analisar a jurisprudência do Superior Tribunal Militar (STM) e recortes doutrinários versando sobre o assunto em pauta.

Em contrapartida, verificaremos alguns dos principais encargos previdenciários e tributários que recaem sobre a categoria, por vezes, muito mais gravosos que os suportados pelas demais carreiras de estado e, mesmo, as civis. Muitas vezes, grandes questionamentos surgem, por parte da população, em decorrência da ignorância acerca do regime jurídico próprio dos militares das Forças Armadas. 


\section{A PERDA DO POSTO E DA PATENTE NA CONSTITUIÇÃO FEDERAL DE 1988}

A Constituição Federal de 1988, nos art. 142 e 143, nos traz importantes dispositivos versando sobre as Forças Armadas. O primeiro, especificamente, introduz as diretrizes da profissão militar federal, incluindo direitos e deveres dos militares:

Art. 142. As Forças Armadas, constituídas pela Marinha, pelo Exército e pela Aeronáutica, são instituições nacionais permanentes e regulares, organizadas com base na hierarquia e na disciplina, sob a autoridade suprema do Presidente da República, e destinam-se à defesa da Pátria, à garantia dos poderes constitucionais e, por iniciativa de qualquer destes, da lei e da ordem.

$[\ldots]$

I - As patentes, com prerrogativas, direitos e deveres a elas inerentes, são conferidas pelo Presidente da República e asseguradas em plenitude aos oficiais da ativa, da reserva ou reformados, sendo-lhes privativos os títulos e postos militares e, juntamente com os demais membros, o uso dos uniformes das Forças Armadas; (Incluído pela Emenda Constitucional nº 18, de 1998)

$[\ldots]$

VI - O oficial só perderá o posto e a patente se for julgado indigno do oficialato ou com ele incompatível, por decisão de tribunal militar de caráter permanente, em tempo de paz, ou de tribunal especial, em tempo de guerra; (Incluído pela Emenda Constitucional $\mathrm{n}^{\circ} 18$, de 1998)

VII - O oficial condenado na justiça comum ou militar a pena privativa de liberdade superior a dois anos, por sentença transitada em julgado, será submetido ao julgamento previsto no inciso anterior; (Incluído pela Emenda Constitucional n ${ }^{\circ} 18$, de 1998) (BRASIL, 1988)

Os princípios basilares da hierarquia e disciplina estão delineados no caput do art. 142, bem como a perenidade da instituição e sua missão constitucional. O seu inciso I infere que a "patente" traz, a reboque, direitos e deveres (muitos delegados à definição legal), além da garantia relacionada a títulos, postos e uso de uniformes.

Entretanto, os incisos VI e VII do art. 142 estão diretamente interligados às garantias de permanência no posto do oficial das Forças Armadas. O texto atual da Carta Magna nos traz notícia de que o oficial, e tempo de paz, só perderá o posto e a patente se for julgado indigno do oficialato ou com ele incompatível, por decisão de tribunal militar de caráter permanente em tempo de paz: no caso, o Superior Tribunal Militar (art. 122, I, combinado com o art, 142, VI, CF/88). Portanto, temos uma fortíssima garantia de permanência no posto imposta pela Lei Maior, no sentido de que o oficial não pode perdê-lo por decisão exclusivamente administrativa - somente por decisão judicial.

O inciso VII do art. 142 prevê que o oficial condenado a pena privativa da liberdade superior a 2 (dois) anos, após o trânsito em julgado em qualquer ramo do Poder Judiciário, será submetido ao julgamento para perda do posto e da patente. 
A atual ordem constitucional introduziu a garantia de que o oficial das Forças Armadas, em tempo de paz, somente será destituído do seu grau hierárquico por intermédio da perda do posto e da patente, caso seja considerado indigno do oficialato ou com ele incompatível, após decisão do STM. Ainda, que o oficial condenado a pena privativa da liberdade superior a 2 (dois) anos, quer pela Justiça Comum ou Militar, será submetido a este julgamento, de forma vinculada.

Curioso mencionar que, no âmbito estadual, diferentemente do federal, e em conformidade com o art. $125, \S 4^{\circ}$, da Lei Maior, também as praças das polícias militares e dos corpos de bombeiros militares somente serão exoneradas (perda da graduação) após a decisão do tribunal competente:

$\S 4^{\circ}$ Compete à Justiça Militar estadual processar e julgar os militares dos Estados, nos crimes militares definidos em lei e as ações judiciais contra atos disciplinares militares, ressalvada a competência do júri quando a vítima for civil, cabendo ao tribunal competente decidir sobre a perda do posto e da patente dos oficiais e da graduação das praças. (BRASIL, 1988)

Portanto, o constituinte de 1988, embora tenha conferido tratamento semelhante aos oficiais das Forças Armadas e aos oficiais das Forças Auxiliares (Polícias Militares e Corpos de Bombeiros Militares), o fez de forma diferenciada em relação às praças.

\section{A PERda dO POSTO E DA PATENTE NO CÓdigo PENAL MILITAR}

\section{(DECRETO-LEI 1.001/69)}

O Código Penal Militar comina, dentre outras, as seguintes penas acessórias:

CAPÍTULO V

DAS PENAS ACESSÓRIAS

Penas Acessórias

Art. 98. São penas acessórias:

I - a perda de posto e patente;

II - a indignidade para o oficialato;

III - a incompatibilidade com o oficialato;

IV - a exclusão das forças armadas;

[...]

Perda de posto e patente

Art. 99. A perda de posto e patente resulta da condenação a pena privativa de liberdade por tempo superior a dois anos, e importa a perda das condecorações.

Indignidade para o oficialato 
Art. 100. Fica sujeito à declaração de indignidade para o oficialato o militar condenado, qualquer que seja a pena, nos crimes de traição, espionagem ou cobardia, ou em qualquer dos definidos nos arts. 161, 235, 240, 242, 243, 244, 245, $251,252,303,304,311$ e 312.

Incompatibilidade com o oficialato

Art. 101. Fica sujeito à declaração de incompatibilidade com o oficialato o militar condenado nos crimes dos arts. 141 e 142.

Exclusão das forças armadas

Art. 102. A condenação da praça a pena privativa de liberdade, por tempo superior a dois anos, importa sua exclusão das forças armadas. (BRASIL, 1969)

A perda do posto e da patente, segundo o diploma repressivo castrense, resulta da condenação do oficial a pena privativa da liberdade superior a 2 (dois) anos. Este dispositivo é compatível com a atual ordem constitucional e traduz a perda do posto do oficial pela via exclusivamente judicial.

O militar fica sujeito à declaração de indignidade para o oficialato quando condenado pelos crimes de crimes de traição, espionagem, cobardia, desrespeito a símbolo nacional, pederastia ou outro ato de libidinagem, furto simples, roubo simples, extorsão simples, extorsão mediante sequestro, chantagem, estelionato, abuso de pessoa, peculato, peculato mediante aproveitamento do erro de outrem, falsificação de documento e falsidade ideológica.

Poderá o militar ser declarado incompatível com o oficialato se for condenado pelos crimes de entendimento para gerar conflito ou divergência com o Brasil ou:

$[\ldots]$

Tentar:

I - Submeter o território nacional, ou parte dele, à soberania de país estrangeiro;

II - Desmembrar, por meio de movimento armado ou tumultos planejados, o território nacional, desde que o fato atente contra a segurança externa do Brasil ou a sua soberania;

III - Internacionalizar, por qualquer meio, região ou parte do território nacional:

[...] (BRASIL, 1969)

Desta forma, o Código Penal Militar prevê que o Oficial das Forças Armadas poderá perder seu cargo, como consequência da perda do posto e da patente, em decorrência da condenação, transitada em julgado, pelo cometimento de alguns crimes específicos.

\section{A PERda do POSTO E DA PATENTE NO CÓdigo DE PROCESSO PENAL MILITAR (DECRETO-LEI 1.002/69)}

O Código de Processo Penal Militar prevê tão somente a necessidade de comunicação, pela Justiça Militar, à autoridade administrativa militar da decisão em que sopese a perda do 
posto e da patente do oficial condenado, confirmando a necessidade de pronunciamento judicial.

\begin{abstract}
Comunicação
Art. 604. O auditor dará à autoridade administrativa competente conhecimento da sentença transitada em julgado, que impuser a pena de reforma ou suspensão do exercício do posto, graduação, cargo ou função, ou de que resultar a perda de posto, patente ou função, ou a exclusão das forças armadas. (BRASIL, 1969)
\end{abstract}

Este diploma castrense, embora sucinto ao abortar a temática proposta, traz comando importante no sentido de regulamentar a comunicação obrigatória entre as esferas judicial e administrativa, para o trâmite do procedimento para a perda do cargo.

\title{
5 A PERDA DO POSTO E DA PATENTE NA LEI DO CONSELHO DE JUSTIFICAÇÃO (LEI 5.836/72)
}

O Conselho de Justificação é, na realidade, verdadeiro tribunal de honra, ou seja: essencialmente de natureza moral, regulado em legislação especial e com a finalidade precípua de analisar fatos que digam respeito à conduta do oficial (FAGUNDES, 1974). Não tem o escopo de perquirir o cometimento de transgressões disciplinares ou crimes - isto já deve ter sido apurado por intermédio de processo administrativo, no primeiro caso, e judicial, no segundo.

No tocante à esfera criminal, o art. 16 da Lei do Conselho de Justificação está em consonância com os dispositivos anteriormente visitados.

Art. $2^{\circ}$ É submetido a Conselho de Justificação, a pedido ou "ex officio" o oficial das forças armadas:

I - acusado oficialmente ou por qualquer meio lícito de comunicação social de ter:

a) procedido incorretamente no desempenho do cargo;

b) tido conduta irregular; ou

c) praticado ato que afete a honra pessoal, o pundonor militar ou o decoro da classe;

II - considerado não habilitado para o acesso, em caráter provisório, no momento em que venha a ser objeto de apreciação para ingresso em Quadro de Acesso ou Lista de Escolha;

III - afastado do cargo, na forma do Estatuto dos Militares por se tornar incompatível com o mesmo ou demonstrar incapacidade no exercício de funções militares a ele inerentes, salvo se o afastamento é decorrência de fatos que motivem sua submissão a processo;

IV - condenado por crime de natureza dolosa, não previsto na legislação especial concernente a segurança do Estado, em Tribunal civil ou militar, a pena restrita de liberdade individual até 2 (dois) anos, tão logo transite em julgado a sentença; ou $\mathrm{V}$ - pertencente a partido político ou associação, suspensos ou dissolvidos por força de disposição legal ou decisão judicial, ou que exerçam atividades prejudiciais ou perigosas à segurança nacional.

$[\ldots]$

Art. 16. O Superior Tribunal Militar, caso julgue provado que o oficial é culpado de ato ou fato previsto nos itens I, III e V, do artigo $2^{\circ}$ ou que, pelo crime cometido, 
previsto no item IV, do artigo $2^{\circ}$, é incapaz de permanecer na ativa ou na inatividade, deve, conforme o caso:

I - Declará-lo indigno do oficialato ou com ele incompatível, determinando a perda de seu posto e patente; ou II - Determinar sua reforma.

$\S 1^{\circ}$ A reforma do oficial é efetuada no posto que possui na ativa, com proventos proporcionais ao tempo de serviço.

$\S 2^{\circ}$ A reforma do oficial ou sua demissão "ex officio" consequente da perda de posto e patente, conforme o caso, é efetuado pelo Ministro Militar respectivo ou encaminhada ao Presidente da República, tão logo seja publicado o acórdão do Superior Tribunal Militar. (BRASIL, 1972)

Acerca da esfera administrativa, temos que o oficial poderá perder seu posto em virtude de determinadas modalidades de conduta assinaladas no art. $2^{\circ}$ da norma em comento. Todavia, faz-se necessário que estes dispositivos sejam submetidos à interpretação conforme a Constituição, nunca nos afastando da assertiva onde o oficial só perde o posto e a patente quando declarado indigno do oficialato ou com ele incompatível, em tempo de paz, após decisão exarada pelo Superior Tribunal Militar. Neste caso, o procedimento nunca poderá ser exclusivamente administrativo, sob pena de violação da Carta Magna, tornando-se verdadeiramente híbrido (ASSIS, 2012), ou seja, administrativo-judicial: inicia administrativamente e encerra na esfera judicial.

Note-se que, com isto, não se quer dizer que todos os procedimentos do Conselho de Justificação serão híbridos (administrativo-judicial). Poderão encerra-se na esfera administrativa aqueles que culminarem em absolvição ou reforma administrativa. Porém, aqueles que acarretarem na conclusão de que o oficial é culpado e ensejarem a perquirição da indignidade ou incompatibilidade para o oficialato (e consequente perda do posto e da patente) serão, necessariamente, híbridos, haja vista a garantia constitucional do julgamento pelo Superior Tribunal Militar. Também, a apreciação do feito pela corte castrense não se amolda em sede recursal da decisão do tribunal de honra - trata-se de uma complementação judicial daquele processo administrativo.

\section{A PERda do POSTO E DA PATENTE NO ESTATUTO DOS MilitARES (LEI 6.880/80)}

O Estatuto dos Militares também adentra a seara da perda do posto e da patente em seu art. 94, ao tratar das formas de exclusão do serviço ativo. Uma vez mais, devemos interpretar este comando à luz da norma constitucional. Por ser uma norma eminentemente administrativa, o oficial tem a garantia de, mesmo infringindo seus ditames, haver assegurado o julgamento pelo Superior Tribunal Militar. 
Art. 94. A exclusão do serviço ativo das Forças Armadas e o consequente desligamento da organização a que estiver vinculado o militar decorrem dos seguintes motivos:

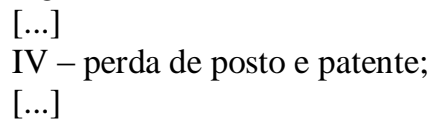

Art. 118. O oficial perderá o posto e a patente se for declarado indigno do oficialato, ou com ele incompatível, por decisão do Superior Tribunal Militar, em tempo de paz, ou de Tribunal Especial, em tempo de guerra, em decorrência de julgamento a que for submetido.

Parágrafo único. O oficial declarado indigno do oficialato, ou com ele incompatível, e condenado à perda de posto e patente só poderá readquirir a situação militar anterior por outra sentença dos tribunais referidos neste artigo e nas condições nela estabelecidas.

Art. 119. O oficial que houver perdido o posto e a patente será demitido ex officio sem direito a qualquer remuneração ou indenização e receberá a certidão de situação militar prevista na legislação que trata do serviço militar.

Art. 120. Ficará sujeito à declaração de indignidade para o oficialato, ou de incompatibilidade com o mesmo, o oficial que:

I - For condenado, por tribunal civil ou militar, em sentença transitada em julgado, à pena restritiva de liberdade individual superior a 2 (dois) anos;

II - For condenado, em sentença transitada em julgado, por crimes para os quais o Código Penal Militar comina essas penas acessórias e por crimes previstos na legislação especial concernente à segurança do Estado;

III - Incidir nos casos, previstos em lei específica, que motivam o julgamento por Conselho de Justificação e neste for considerado culpado; e

IV - Houver perdido a nacionalidade brasileira. (BRASIL, 1980)

Cabe enfatizar que o estatuto castrense logrou delinear a interpretação autêntica do conceito de "posto", em seu art. $16, \S 1^{\circ}$, a saber: "posto é o grau hierárquico do oficial, conferido por ato do Presidente da República ou do Ministro de Força Singular e confirmado em Carta Patente". O art. 50, I, do mesmo diploma, explicita que é direito do militar "a garantia da patente em toda a sua plenitude, com as vantagens, prerrogativas e deveres a ela inerentes, quando oficial, nos termos da Constituição", harmonizando-se com o precitado conceito de "patente", concernente à Carta Política em vigor. A perda do posto e da patente é, pois, o despojamento do grau hierárquico do oficial, com a extinção dos direitos e deveres a ele inerentes, em virtude de conduta indigna ou incompatível, aplicável ao militar da ativa, da reserva ou reformado.

A Lei 6.880/80, em seus art. 20 a 23, trata da definição de "cargo" e "função" militares: 
Art. 20. Cargo militar é um conjunto de atribuições, deveres e responsabilidades cometidos a um militar em serviço ativo.

$\S 1^{\circ} \mathrm{O}$ cargo militar, a que se refere este artigo, é o que se encontra especificado nos Quadros de Efetivo ou Tabelas de Lotação das Forças Armadas ou previsto, caracterizado ou definido como tal em outras disposições legais.

$\S 2^{\circ}$ As obrigações inerentes ao cargo militar devem ser compatíveis com o correspondente grau hierárquico e definidas em legislação ou regulamentação específicas.

Art. 21. Os cargos militares são providos com pessoal que satisfaça aos requisitos de grau hierárquico e de qualificação exigidos para o seu desempenho.

Parágrafo único. O provimento de cargo militar far-se-á por ato de nomeação ou determinação expressa da autoridade competente.

Art. 22. O cargo militar é considerado vago a partir de sua criação e até que um militar nele tome posse, ou desde o momento em que o militar exonerado, ou que tenha recebido determinação expressa da autoridade competente, o deixe e até que outro militar nele tome posse de acordo com as normas de provimento previstas no parágrafo único do artigo anterior.

[...]

Art. 23. Função militar é o exercício das obrigações inerentes ao cargo militar. (BRASIL, 1980)

Portanto, o objeto da presenta análise versa sobre a garantia de permanência no posto do oficial (grau hierárquico) e, subsequentemente, a patente (direitos e deveres), não meramente no cargo militar (conjunto de atribuições) ou função (exercício do cargo militar).

\section{A VITALICIEDADE DO OFICIAL NA LEI DE ORGANIZAÇÃO JUDICIÁRIA MILITAR (LEI 8.457/92)}

A Lei de Organização Judiciária Militar da União, ao enumerar a competência originária do Superior Tribunal Militar, informa sua prerrogativa de julgar a representação para decretação de indignidade ou incompatibilidade com o oficialato.

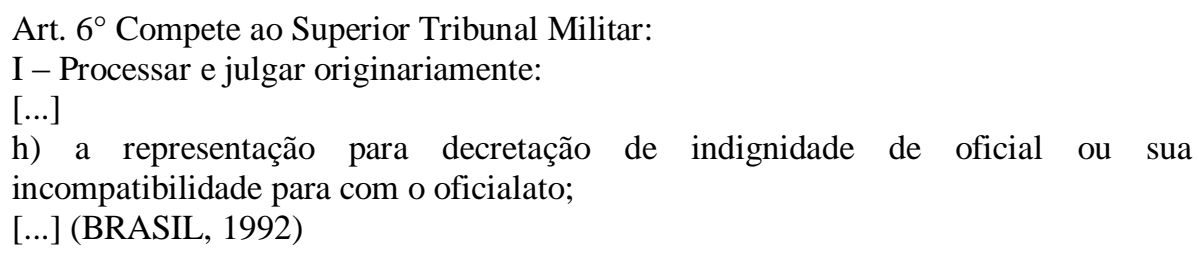

Da inteligência do art. 18 da norma em tela, extraímos a menção ao termo "vitaliciedade", quando trata-se dos juízes militares a serem sorteados para os Conselhos Especial e Permanente de Justiça. Portanto, a Lei de Organização Judiciária Militar da União reconheceu, indubitavelmente, que os oficiais de carreira das Forças Armadas - universo apto a compor tais escabinatos - não gozam de simples estabilidade, mas possuem verdadeira vitaliciedade assegurada (ROTH, 2015).

Art. 18. Os juízes militares dos Conselhos Especial e Permanente são sorteados dentre oficiais de carreira, da sede da Auditoria, com vitaliciedade assegurada, 
recorrendo-se a oficiais no âmbito de jurisdição da Auditoria se insuficientes os da sede e, se persistir a necessidade, excepcionalmente a oficiais que sirvam nas demais localidades abrangidas pela respectiva Circunscrição Judiciária Militar. (Redação dada pela Lei ${ }^{\circ} 10.445$, de 7.5.2002) (ROTH, 2015)

Estes mesmos ditames foram reverberados na jurisprudência deste tribunal militar, ao julgar o Desaforamento 0000001-42.2007.7.10.0010 (2007.01.000400-8) / CE, de 15 AGO 07:

CONSELHO ESPECIAL DE JUSTIÇA. DESAFORAMENTO. INEXISTÊNCIA DE OFICIAIS DA SEDE DA AUDITORIA OU NA JURISDIÇÃO DO JUÍZO EM CONDIÇÕES DE SEREM SORTEADOS JUÍZES MILITARES DO REFERIDO CONSELHO.

I - Os juízes militares dos Conselhos de Justiça devem ser sorteados entre os oficiais de carreira da sede da auditoria, com vitaliciedade assegurada ou, excepcionalmente, entre os oficiais que sirvam nas localidades jurisdicionadas à respectiva Circunscrição Judiciária Militar (Inteligência do artigo 18 da Lei no 8.457/92 (LOJM), com a redação dada pela Lei $n^{\circ} 10.445$, de 07/05/2002).

II - No caso concreto, não foi possível constituir o Conselho Especial de Justiça na Auditoria da $10^{\mathrm{a}} \mathrm{CJM}$, por inexistir oficiais (na sede da Auditoria ou mesmo na jurisdição do Juízo), em condições de serem sorteados juízes militares. Assim sendo, impõe-se o Desaforamento do respectivo processo para a Auditoria mais próxima do Juízo de origem, onde possua oficiais em número suficiente e em condições de serem sorteados juízes militares do referido Conselho, ou seja, a Auditoria da $7^{\text {a }}$ CJM.

Deferido o pedido de Desaforamento requerido pelo Juízo a quo por Decisão unânime. (STM, 2007)

Desta forma, a Justiça Militar da União vem sinalizando que o oficial das Forças Armadas detém a prerrogativa da vitaliciedade, ao invés da mera estabilidade.

\section{A PERda do POSTO E dA PATENTE E O MINISTÉRIO PÚBLICO MILITAR (MPM)}

Questão controversa repousa na fase judicial do procedimento para perda do posto e da patente do oficial, quando oriundo dos Conselhos de Justificação. Utilizando-se uma interpretação meramente literal das normas envolvidas, teríamos verdadeiro processo sem parte, haja vista o encaminhamento dos autos, de ofício, pela autoridade administrativa para o Superior Tribunal Militar. Em suma, não haveria um legitimado para provocar a manifestação daquele órgão do Poder Judiciário.

No "I Encontro Nacional do Ministério Público com Atuação Perante a Justiça Militar", ocorrido em 11 de junho de 2015, o Grupo de Trabalho III, ao abordar o tema "O rito processual para perda do posto e da graduação dos militares", chegou a valorosas conclusões, que podemos depreender se sua ementa: 
DECLARAÇÃO DE INDIGNIDADE E INCOMPATIBILIDADE PARA O OFICIALATO COM A CONSEQUENTE PERDA DO POSTO E PATENTE DOS OFICIAIS. PROCESSO DECORRENTE DO CONSELHO DE JUSTIFICAÇÃO. CARÁTER JUDICIAL DO REFERIDO PROCESSO. LEGITIMIDADE EXCLUSIVA DO MINISTÉRIO PÚBLICO PARA REQUERER AO TRIBUNAL COMPETENTE. INCOMPATIBILIDADE DA LEI 5.836/1972 COM A CARTA POLÍTICA DE 1988.

Portanto, é o Ministério Público Militar quem deve compor o polo ativo da relação jurídica nos feitos perante a corte castrense oriundos dos Conselhos de Justificação. Não obstante, a Lei Complementar 75/93 (Estatuto do Ministério Público da União) assegura ao Ministério Público Militar a atribuição de promover, perante a Justiça Militar, a declaração de indignidade ou incompatibilidade com o oficialato.

Art. 116. Compete ao Ministério Público Militar o exercício das seguintes atribuições junto aos órgãos da Justiça Militar:

$[\ldots]$

II - promover a declaração de indignidade ou de incompatibilidade para o oficialato; [...] (BRASIL, 1993)

O Ministério Público Militar, portanto, tem papel fundamental durante os procedimentos para perda do cargo do oficial das Forças Armadas.

\section{A PERDA DO POSTO E DA PATENTE NO REGIMENTO INTERNO DO SUPERIOR TRIBUNAL MILITAR (RISTM)}

O Regimento Interno do Superior Tribunal Militar prevê, em seu art. 161, que há possibilidade de 3 (três) possíveis desfechos para o acusado, em virtude do julgamento dos processos oriundos dos Conselhos de Justificação: absolvido, onde conservará seu posto e patente, sem prejuízo das sanções disciplinares ou judiciais cabíveis; culpado, onde perderá seu posto e patente; e incapaz de permanecer na ativa ou inatividade, onde será reformado.

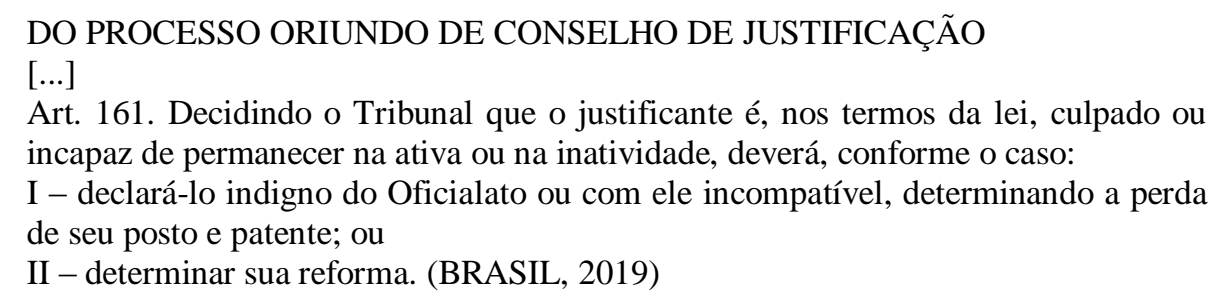

O Regimento Interno da Côrte castrense, desta maneira, implementa que, caso o Oficial não seja absolvido ou lhe seja imposta a reforma, perderá seu cargo, em decorrência dos processos oriundos do Conselho de Justificação. 


\section{A VITALICIEDADE DO POSTO DE OFICIAL DAS FORÇAS ARMADAS}

Segundo MAZZA (2015), é possível identificar 2 (dois) regimes jurídicos diferentes aplicáveis aos servidores estatutários. O primeiro é a vitaliciedade, onde o agente público pode perder o cargo unicamente por sentença judicial transitada em julgado, adquirida após um estágio probatório reduzido de 2 (dois) anos de efetivo serviço, do qual são exemplos os magistrados, os membros do Ministério Público e dos tribunais de contas. O segundo, a estabilidade, que exige um estágio probatório de 3 (três) anos, na qual o agente público pode ser destituído do cargo por sentença judicial ou processo administrativo, e seriam exemplos todos os demais estatutários. Saliente-se que o "cargo", em Direito Administrativo, afasta-se do conceito de "cargo militar" do Estatuto dos Militares, e aproxima-se do conceito de "posto" para os oficiais e "graduação" para as praças.

Como vislumbramos anteriormente, os oficiais das Forças Armadas detêm a prerrogativa constitucional de somente ser destituídos do posto (cargo), em tempo de paz, após decisão do Superior Tribunal Militar. Isto ocorre mesmo no caso de procedimento originariamente administrativo, como os provenientes dos Conselhos de Justificação. Portanto, da inteligência dos diversos dispositivos mencionados e da doutrina e jurisprudência colacionadas, ao oficial das Forças Armadas é deferida a prerrogativa da vitaliciedade, não mera estabilidade.

Sem embargo, esta vitaliciedade do oficial é mais pronunciada que a dos demais agentes submetidos a este regime, por prescinde de estágio probatório: basta a assunção do primeiro posto para que possa produzir seus efeitos.

Certamente, não estamos nos referindo aos casos de condenação por reforma, haja vista que o oficial não fica privado de seu posto e patente, apenas abandona o serviço ativo. Também, não há incompatibilidade com a situação do oficial temporário, sempre sobrepairando a ideia de que sua investidura é precária - ao final do tempo de serviço, será licenciado.

É valido salientar, ainda, que qualquer integrante de cargo público poderá perdê-lo em virtude de condenação por crime de improbidade administrativa, em conformidade com a Lei $\mathrm{n}^{\circ}$ 8.249/92 (BRASIL, 1992) - inclusive os oficias das Forças Armadas - independentemente das precitadas prerrogativas.

11 A CARGA PREVIDENCIÁRIA E TRIBUTÁRIA DOS INTEGRANTES DAS FORÇAS ARMADAS 
Inicialmente, inculpe o espectro salientar que o militar das Forças Armadas não possui um regime previdenciário na acepção literal do vocábulo, como é próprio nas carreiras civis. Ao menos, da forma como é arquitetada alhures: trata-se de um sistema de proteção previdenciária, que consegue ser muito mais complexo do que o regime geral de previdência social e o regime próprio de previdência social. Isto ocorrem na maior parte do mundo, haja vista que, enquadrar o militar federal em algum desses regimes ordinários seria inviabilizar o funcionamento da instituição castrense, o que pretenderemos comprovar, na sequência.

A Constituição Federal de 1988 (BRASIL, 1988), nos informa, em seu artigo 6º que: "São direitos sociais a educação, a saúde, a alimentação, o trabalho, a moradia, o transporte, o lazer, a segurança, a previdência social, a proteção à maternidade e à infância, a assistência aos desamparados, na forma desta Constituição”. Portanto, cabe aos militares, também, dentre outros, o direito à saúde, ao trabalho, à moradia, ao transporte e à previdência social.

A Medida Provisória 2.215/01 (BRASIL, 2001), nos dá notícia de que os descontos obrigatórios do militar da ativa e inativo são:

\footnotetext{
Art. 15. São descontos obrigatórios do militar:

I - contribuição para a pensão militar;

II - contribuição para a assistência médico-hospitalar e social do militar;

III - indenização pela prestação de assistência médico-hospitalar, por intermédio de organização militar;

IV - impostos incidentes sobre a remuneração ou os proventos, de acordo com a lei;

V - indenização à Fazenda Nacional em decorrência de dívida;

VI - pensão alimentícia ou judicial;

VII - taxa de uso por ocupação de próprio nacional residencial, conforme regulamentação;

VIII - multa por ocupação irregular de próprio nacional residencial, conforme regulamentação. (BRASIL, 2001)
}

Portanto, o militar federal, em serviço ativo ou inativo, contribui para a pensão militar (natureza de seguridade social), para a assistência médico-hospitalar e social (natureza de seguridade social), imposto sobre a renda (da mesma forma que incide sobre o trabalhador civil, e na fonte), pensão alimentícia ou judicial (da mesma forma que suporta o alimentante trabalhador civil), dentre outras. Ressalte-se que a seguridade social engloba a previdência social, a assistência social e a saúde, conforme artigo 194 da Constituição Federal (“Art. 194. A seguridade social compreende um conjunto integrado de ações de iniciativa dos Poderes Públicos e da sociedade, destinadas a assegurar os direitos relativos à saúde, à previdência e à assistência social").

Cumpre enfatizar que, mesmo em situação de inatividade, o militar federal continua contribuindo para a seguridade social, a saber: pensão militar e assistência médico-hospitalar 
e social. O trabalhador civil, no regime geral de previdência social (e mesmo nos regimes próprios), não contribui com a previdência social quando aposentado, por força do Capítulo I do Título VI da Lei 8.212/91 (BRASIL, 1991). Quanto à saúde, o civil não contribui nem periodicamente, nem por atendimento, para os serviços estatais de saúde, haja vista a universalidade e gratuidade do Sistema Único de Saúde (SUS), com base nos artigos 196 e 197 da Lei Maior:

Art. 196. A saúde é direito de todos e dever do Estado, garantido mediante políticas sociais e econômicas que visem à redução do risco de doença e de outros agravos e ao acesso universal e igualitário às ações e serviços para sua promoção, proteção e recuperação.

Art. 197. São de relevância pública as ações e serviços de saúde, cabendo ao Poder Público dispor, nos termos da lei, sobre sua regulamentação, fiscalização e controle, devendo sua execução ser feita diretamente ou através de terceiros e, também, por pessoa física ou jurídica de direito privado. (BRASIL, 1988)

Este princípio vem reverberado no artigo $2^{\circ}$ da Lei 8.212/91 (BRASIL, 1991):

Art. $2^{\circ}$ A Saúde é direito de todos e dever do Estado, garantido mediante políticas sociais e econômicas que visem à redução do risco de doença e de outros agravos e ao acesso universal e igualitário às ações e serviços para sua promoção, proteção e recuperação.

Parágrafo único. As atividades de saúde são de relevância pública e sua organização obedecerá aos seguintes princípios e diretrizes:

a) acesso universal e igualitário;

b) provimento das ações e serviços através de rede regionalizada e hierarquizada, integrados em sistema único;

c) descentralização, com direção única em cada esfera de governo;

d) atendimento integral, com prioridade para as atividades preventivas;

e) participação da comunidade na gestão, fiscalização e acompanhamento das ações e serviços de saúde;

f) participação da iniciativa privada na assistência à saúde, obedecidos os preceitos constitucionais. (BRASIL, 1991)

No tocante aos militares federais, a assistência médico-hospitalar é regulamentada pelo Decreto $n^{\circ}$ 92.512/86 - Estabelece normas, condições de atendimento e indenizações para a assistência médico-hospitalar ao militar e seus dependentes, e dá outras providências (BRASIL, 1986). O seu artigo 14, com redação modificada pelo Decreto 4.307/02 Regulamenta a Medida Provisória no 2.215-10, de 31 de agosto de 2001, que dispõe sobre a reestruturação da remuneração dos militares das Forças Armadas, altera as Leis nos 3.765, de 4 de maio de 1960, e 6.880, de 9 de dezembro de 1980, e dá outras providências (BRASIL, 2002), dispõe que "A contribuição de até três e meio por cento ao mês, para constituição do Fundo de Saúde, de cada Força Armada, será estabelecida pelo respectivo Comandante da Força”. Ainda, que "Art. 32. Os beneficiários dos Fundos de Saúde de cada Força estarão 
sujeitos ao pagamento de 20\%.(vinte por cento) das indenizações devidas pela assistência médico-hospitalar que lhes for prestada em organizações de saúde das Forças Armadas, ou através de convênios ou contratos, sendo o restante coberto com os recursos financeiros relacionados no Título III, conforme regulamentação de cada Força”. Especificamente no caso do Exército Brasileiro, à guisa exemplificativa, a assistência médico-hospitalar e social é prestada pelo Fundo de Saúde do Exército (FUSEX), regido pela Portaria no 653/05 - Aprova as Instruções Gerais para o Fundo de Saúde do Exército (IG 30-32) e dá outras providências (BRASIL, 2005) e pela Portaria $n^{\circ}$ 049/08 - Aprova as Instruções Reguladoras para o Gerenciamento do Cadastro de Beneficiários do FUSEX (IR 30-39) (BRASIL, 2008). Estes dispositivos impõem que os militares, ativos e inativos, contribuam com 3,5\% (três e meio por cento) de seus vencimentos brutos por mês com saúde, além de uma participação de $20 \%$ (vinte por cento) em caso de atendimento. Para o civil, não se paga nem um, nem outro.

Acerca da pensão militar, a Lei 3.765/60 trata do assunto. Em seu artigo $1^{\circ}$, temos que todos os militares, da ativa ou da reserva, contribuem com a pensão militar: "São contribuintes obrigatórios da pensão militar, mediante desconto mensal em folha de pagamento, todos os militares das Forças Armadas”. O artigo $3^{\circ}$-A e seu parágrafo único, trazem a alíquota: “Art. 3o-A. A contribuição para a pensão militar incidirá sobre as parcelas que compõem os proventos na inatividade [...] Parágrafo único. A alíquota de contribuição para a pensão militar é de sete e meio por cento".

Em suma: o sistema de proteção ao militar, que configura sua seguridade social, integrando previdência social, assistência social e saúde, é custeada pelo próprio militar federal, na ativa e mesmo depois que é transferido para a reserva remunerada e para a reforma. A alíquota é de 3,5 (três e meio porcento), no tocante ao FUSEX, e 7,5 (sete e meio porcento), relativamente à pensão militar; perfazendo $11 \%$ (onze porcento), idêntica à suportada pelo trabalhador civil, em regime geral ou próprio previdenciários. Ademais, o militar federal contribui na ativa e na reserva, sobre o valor bruto dos seus vencimentos e, caso necessite de atendimento médico, deverá pagar $20 \%$ do valor da despesa (estes últimos, sem par no meio civil).

Outro aspecto que é importante destacar é o fato de que, na inatividade (reserva remunerada e reforma), ao contrário do senso comum, as despesas com pagamento de pessoal são custeadas pelo Ministério da Defesa, não causando qualquer repercussão no orçamento destinado à Previdência Social. Somente o pagamento de pensionistas de militares é custeado, parcialmente, com recursos previdenciários, nos moldes do que ocorre com as demais 
carreiras civis, sejam de estado ou não. O impacto econômico das despesas com pensão militar pode ser observado no esquema abaixo, sendo o menos gravoso dentre todos os demais sistemas.

Slide 01 - Situação financeira do sistema previdenciário, BPC e pensões militares

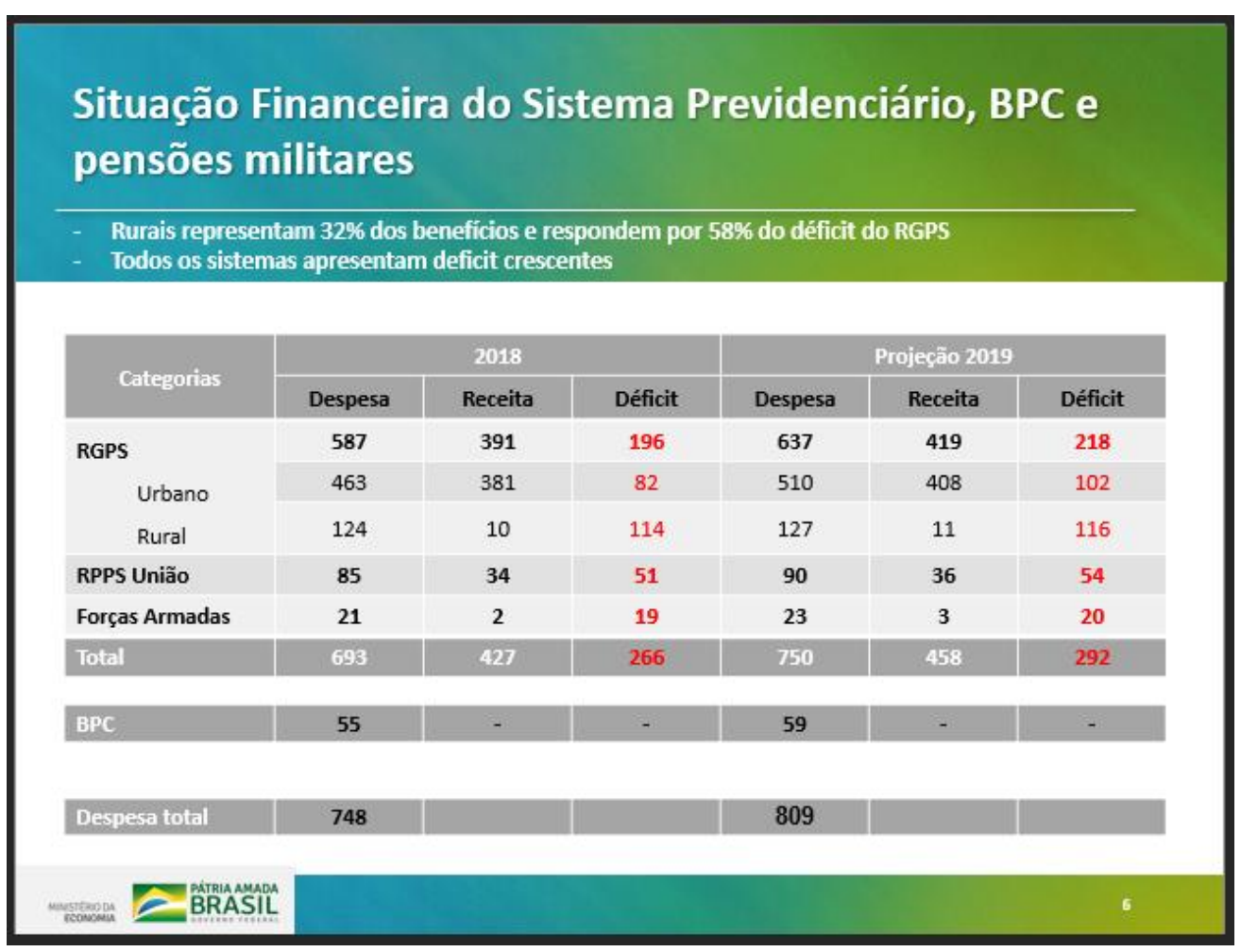

Fonte: Ministério da Economia - Governo Federal, 2019.

\section{CONCLUSÃO}

Nos quadros abaixo, temos um resumo da dinâmica dos procedimentos para perda do posto e da patente:

Quadro 01 - Procedimento exclusivamente judicial

\begin{tabular}{|c|c|}
\hline \multicolumn{2}{|c|}{ PROCEDIMENTO EXCLUSIVAMENTE JUDICIAL } \\
\hline $\begin{array}{c}1^{\text {a }} \text { FASE (PROCESSO JUDICIAL) } \\
\text { pficial condenado a pena privativa da liberdade por } \\
\text { prazo superior a 2 (dois) anos na justiça comum ou } \\
\text { militar }\end{array}$ & \begin{tabular}{c}
$2^{\mathrm{a}}$ FASE (PROCESSO JUDICIAL) \\
Julgamento para perda do posto e da patente pelo \\
\hline Art 142, VII, CF/88 \\
Art 99 do CPM \\
Art 120, I, Lei 6.880/80
\end{tabular} Art 142, VI, CF/88 \\
\hline
\end{tabular}




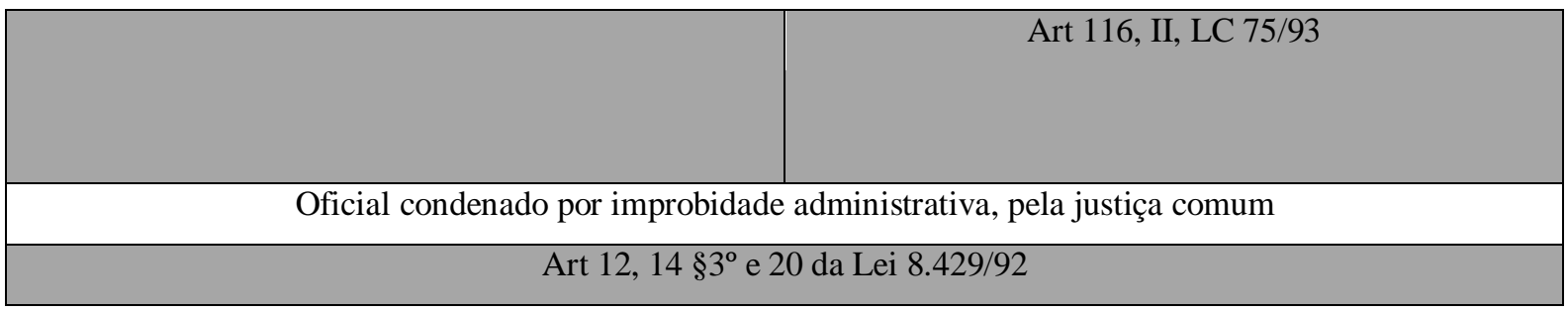

Fonte: o autor.

Quadro 02 - Procedimento administrativo-judicial (híbrido)

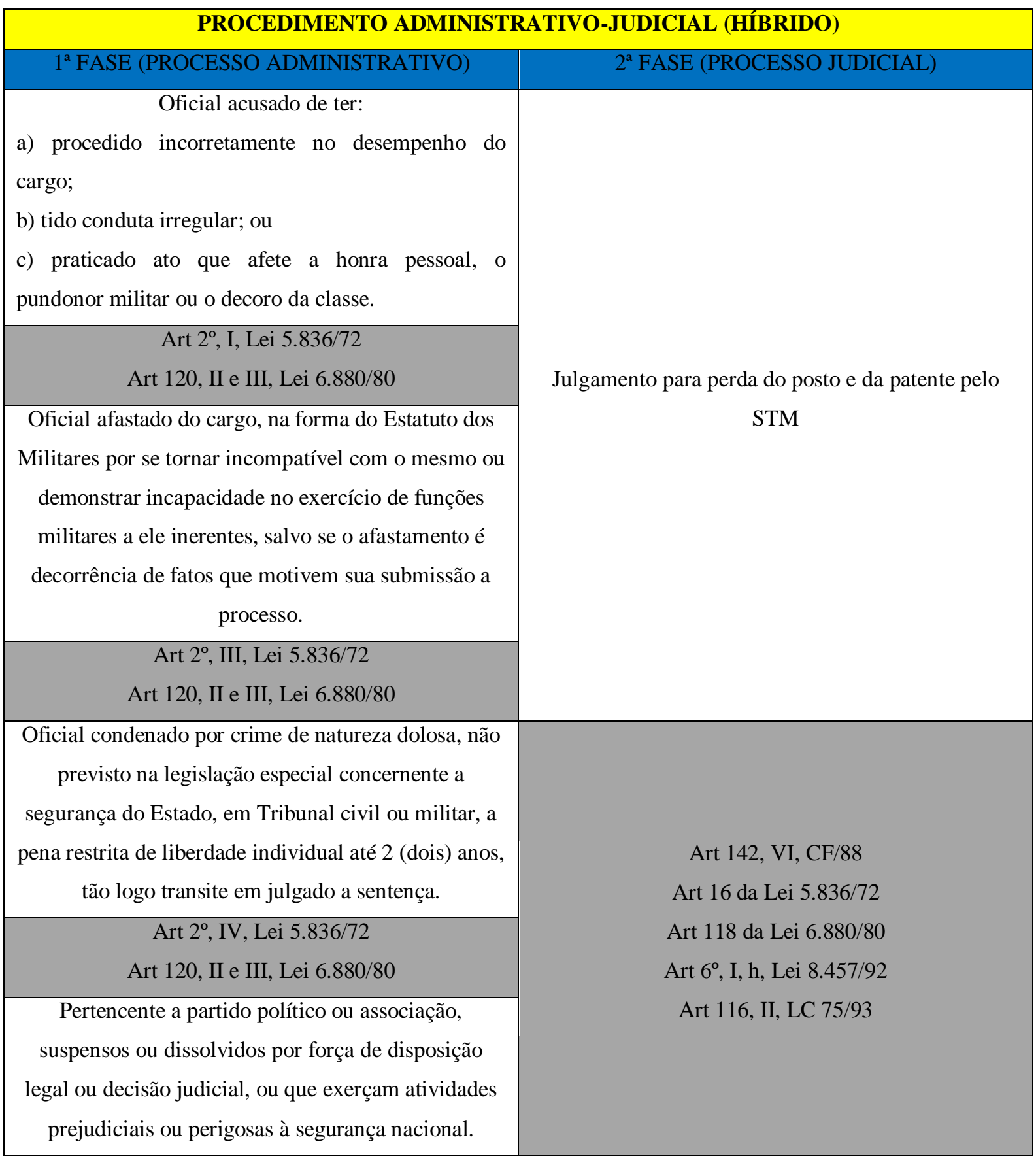




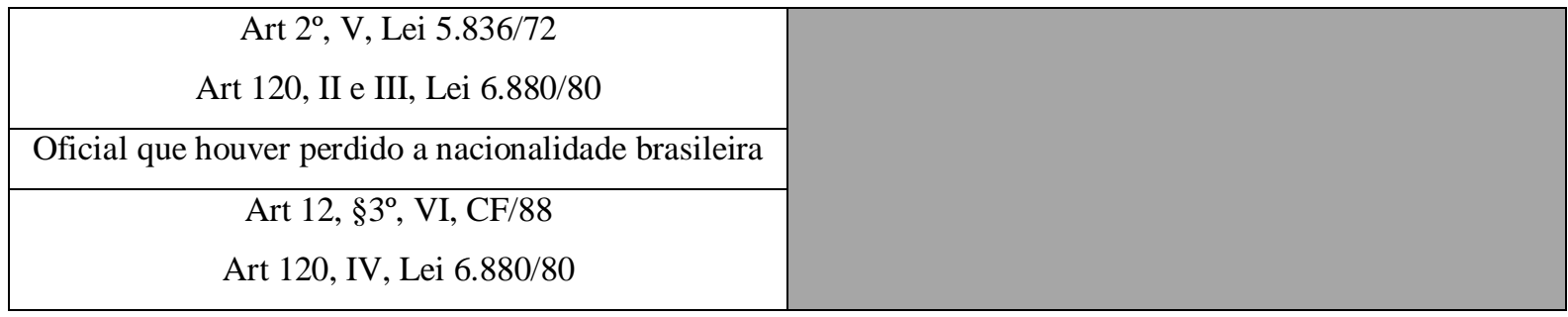

Fonte: o autor.

Os possíveis desfechos da $2^{\mathrm{a}}$ fase dos procedimentos acima descritos são os seguintes:

a) Absolvição: onde o oficial conserva seu posto e patente, sem prejuízo das sanções criminais e/ou disciplinares apuradas na $1^{\text {a }}$ fase.

b) Reforma (condenação): onde o oficial conserva seu posto e patente, mas abandona o serviço ativo (art. 16, II, Lei 5.836/72 e art. 161, II, RISTM.

c) Perda do posto e da patente (condenação): onde o oficial será demitido ex officio, sem direito a qualquer remuneração ou indenização e receberá a certidão de situação militar prevista na legislação que trata do serviço militar (art. 16, I, Lei 5.836/72; art. 94, IV combinado com os art. 118 e 119 da Lei 6.880/80; art. 161, I, RISTM).

O oficial das Forças Armadas goza da garantia constitucional da vitaliciedade, ou seja, somente poderá ser destituído de seu grau hierárquico por decisão judicial, por intermédio da perda do posto e da patente, após a declaração de indignidade ou incompatibilidade com o oficialato. Em tempo de paz, o órgão com jurisdição para tal pronunciamento derradeiro é o Superior Tribunal Militar, independentemente de o procedimento ser exclusivamente judicial, ou híbrido administrativo-judicial. Ombreia, assim, com a proteção social previdenciária e trabalhista que é afeta aos magistrados, membros do Ministério Público e ministros dos Tribunais de Contas.

Portanto, embora goze da prerrogativa da vitaliciedade (e outras particulares à carreira), o militar federal vê-se, hodiernamente, obrigado a suportar uma carga tributária e previdenciária que, indo de encontro ao senso comum, acaba por ser mais gravosa do que a suportada pelo meio civil. O quadro abaixo busca elucidar esta temática, explicitada no item 11:

Quadro 03 - Comparação entre os regimes previdenciários e tributários

REGIME PREVIDENCIÁRIO-TRIBUTÁRIO MILITAR-CIVIL

\begin{tabular}{|l|l|l|}
\hline BENEFÍCIO / CATEGORIA & MILITAR & CIVIL
\end{tabular}




\begin{tabular}{|c|c|c|}
\hline Previdência Social & $\begin{array}{l}\text { - Possui um sistema de proteção } \\
\text { social } \\
\text { - Contribui para a pensão militar } \\
(7,5 \%) \\
\text { - Contribui na ativa e na reserva }\end{array}$ & $\begin{array}{l}\text { - Possui regime geral e próprio } \\
\text { de previdência social } \\
\text { - Contribui com (11\%) em } \\
\text { média } \\
\text { - Só contribui na atividade }\end{array}$ \\
\hline Saúde & $\begin{array}{l}\text { - Possui um sistema de assistência } \\
\text { médico-hospitalar e social. Ex: } \\
\text { FUSEX. } \\
\text { - Contribui para o sistema }(3,5 \%) \\
\text { - Contribui na ativa e na reserva } \\
\text { - Participa em caso de atendimento } \\
(20 \%)\end{array}$ & - Gratuito \\
\hline
\end{tabular}

Fonte: o autor

As propostas de reforma do sistema de proteção social dos militares tendem a aumentar a alíquota da contribuição da pensão militar para 10,5\% (dez e meio por cento), que irá perfazer, ao somar-se com a contribuição para a assistência médico-hospitalar de 3,5\% (três e meio por cento), um total de $14 \%$ (quatorze por cento), constituindo um dos maiores encargos, desta natureza, no país. Isto está consubstanciado no Projeto de Lei $\mathrm{n}^{\circ} 1.645$, de 20 de março de 2019, que versa sobre o novo sistema de proteção social dos militares (BRASIL, 2019).

As Forças Armadas destinam-se a defender a pátria, as instituições e os poderes constituídos. São o fiador da democracia no mundo livre, o bastião da garantia dos direitos e da imposição dos deveres fundamentais. Mas são caras - não há viabilidade econômica de pagar-se horas extras, adicional noturno, de periculosidade, de insalubridade, dentre outros para profissionais que fazem do risco de vida, da disponibilidade permanente e do poder de projetar força (nacional e internacionalmente), a sua profissão. Portanto, a exequibilidade orçamentária da instituição castrense depende sobremaneira da manutenção de um sistema de proteção social que permita um mínimo de dignidade aos seus integrantes, mesmo cerceando direitos sociais que são impensáveis de se subtrair no meio civil. 


\section{REFERÊNCIAS}

ASSIS, Jorge Cesar de Assis. Direito Militar - Aspectos penais, processuais penais e administrativos. $3^{\mathrm{a}}$ edição. Curitiba: Juruá, 2012.

BRASIL. Constituição da República Federativa do Brasil de 1988. Brasília, DF: Presidência da República Federativa do Brasil. Disponível em $<$ http://www.planalto.gov.br/ccivil_03/constituicao/constituicaocompilado.htm> Acesso em 25 JAN 19.

- Decreto 92.512/86 - Estabelece normas, condições de atendimento e indenizações para a assistência médico-hospitalar ao militar e seus dependentes, e dá outras providências. Brasília, DF: Presidência da República Federativa do Brasil. Disponível em <http://www.planalto.gov.br/ccivil 03/decreto/1980-1989/D92512compilado.htm> Acesso em 25 JAN 19.

. Decreto 4.307/02 - Regulamenta a Medida Provisória no 2.215-10, de 31 de agosto de 2001, que dispõe sobre a reestruturação da remuneração dos militares das Forças Armadas, altera as Leis nos 3.765, de 4 de maio de 1960, e 6.880, de 9 de dezembro de 1980, e dá outras providências. Brasília, DF: Presidência da República Federativa do Brasil. $\quad$ Disponível em <http://www.planalto.gov.br/ccivil_03/decreto/2002/D4307.htm> Acesso em 25 JAN 19.

. Decreto-Lei 1.001, de 21 de outubro de 1969 - Código Penal Militar. Brasília, DF: Presidência da República Federativa do Brasil. Disponível em <http://www.planalto.gov.br/ccivil_03/decreto-lei/Del1001Compilado.htm> Acesso em 25 JAN 19.

. Decreto-Lei 1.002, de 21 de outubro de 1969 - Código de Processo Penal Militar. Brasília, DF: Presidência da República Federativa do Brasil. Disponível em <http://www.planalto.gov.br/ccivil_03/decreto-lei/Del1002Compilado.htm> Acesso em 25 JAN 19.

. Lei 3.765/60 - Dispõe sobre as Pensões Militares. Brasília, DF: Presidência da República $\quad$ Federativa do drasil. $\quad$ Disponível <http://www.planalto.gov.br/ccivil_03/LEIS/L3765compilado.htm> Acesso em 25 JAN 19.

. Lei 5.836/72 - Dispõe sobre o Conselho de Justificação e dá outras providências. Brasília, DF: Presidência da República Federativa do Brasil. Disponível em <http://www.planalto.gov.br/ccivil_03/LEIS/1970-1979/L5836.htm> Acesso em 25 JAN 19.

. Lei 6.880/80 - Estatuto dos Militares. Brasília, DF: Presidência da República Federativa do Brasil. Disponível em <http://www.planalto.gov.br/ccivil 03/LEIS/16880compilada.htm> Acesso em 25 JAN 19.

Lei 8.212/91 - Dispõe sobre a organização da Seguridade Social, institui Plano de Custeio, e dá outras providências. Brasília, DF: Presidência da República Federativa do 
Brasil. Disponível em 〈http://www.planalto.gov.br/ccivil_03/LEIS/L8212compilado.htm> Acesso em 25 JAN 19.

- Lei 8.249/92 - Lei de Improbidade Administrativa. Brasília, DF: Presidência da $\begin{array}{lllll}\text { República } & \text { Federativa } & \text { do } & \text { Brasil. } & \text { Disponível }\end{array}$ <http://www.planalto.gov.br/ccivil_03/leis/18429.htm> Acesso em 25 JAN 19.

. Lei 8.457/92 - Lei de Organização Judiciária Militar. Brasília, DF: Presidência da \begin{tabular}{lllll}
\hline República & Federativa do & Brasil. & Disponível & em
\end{tabular} <http://www.planalto.gov.br/Ccivil_03/LEIS/L8457.htm> Acesso em 25 JAN 19.

. Lei Complementar 75/93 - Estatuto do Ministério Público da União. Brasília, DF: Presidência da República Federativa do Brasil. Disponível em <http://www.planalto.gov.br/Ccivil 03/leis/LCP/Lcp75.htm> Acesso em 25 JAN 19.

. Medida Provisória 2.215-10/01 - Dispõe sobre a reestruturação da remuneração dos militares das Forças Armadas, altera as Leis nos 3.765, de 4 de maio de 1960, e 6.880, de 9 de dezembro de 1980, e dá outras providências. Brasília, DF: Presidência da $\begin{array}{lllll}\text { República } & \text { Federativa do } & \text { Brasil. } & \text { Disponível } & \text { em }\end{array}$ <http://www.planalto.gov.br/ccivil_03/MPV/2215-10.htm> Acesso em 25 JAN 19.

. Portaria no 653/05 - Aprova as Instruções Gerais para o Fundo de Saúde do Exército (IG 30-32) e dá outras providências. Brasília, DF: Presidência da República Federativa do Brasil. Disponível em <http://www.15blog.eb.mil.br/midia/pdf/legislacaosammed-fusex/ig-30-32-fusex.pdf> Acesso em 25 JAN 19.

. Portaria no 049/08 - Aprova as Instruções Reguladoras para o Gerenciamento do Cadastro de Beneficiários do FUSEx (IR 30-39). Brasília, DF: Presidência da República Federativa do Brasil. Disponível em 〈http://apoioasaude.dsau.eb.mil.br/aplicativos/materia/legislacao/Legislacao_FUSEx_IR_Nr3 0-39.pdf> Acesso em 25 JAN 19.

- Projeto de Lei 1.645/19 - Novo Sistema de Proteção Social dos Militares. Brasília, DF: Câmara dos Deputados. Disponível em <https://www.camara.leg.br/proposicoesWeb/fichadetramitacao?idProposicao=2194874>

Acesso em 22 MAR 19.

. Regimento Interno do Superior Tribunal Militar. Brasília, DF: Superior Tribunal Militar. Disponível em <http://www2.stm.jus.br/sislegis/index.php/ctrl publico pdf/visualizar/22449> Acesso em 25 JAN 19.

FAGUNDES, João Batista da Silva. O posto e a patente perante o Conselho de Justificação. Revista de Informação Legislativa. Brasília, no 14, outubro a dezembro de 1974.

MAZZA, Alexandre. Manual de Direito Administrativo. $5^{\text {a }}$ edição. São Paulo: Saraiva, 2018. 
MINISTÉRIO DA ECONOMIA. Apresentação da PEC. 2019. 41 slides. Disponível em <brasil.gov.br/novaprevidencia>. Acesso em 12 MAR 19.

ROTH, Ronaldo João. A incompatibilidade da lei do Conselho de Justificação (Lei Federal no 5.836/72) diante da Constituição Federal. Revista Direito Militar. Florianópolis, $n^{\circ} 112$, março / abril de 2015. 